\title{
CYP3A7*1C allele is associated with reduced levels of 2-hydroxylation pathway oestrogen metabolites
}

\author{
Deepti Sood ${ }^{1}$, Nichola Johnson ${ }^{2}$, Pooja Jain ${ }^{1}$, Alexandros P Siskos ${ }^{1}$, Mark Bennett ${ }^{3}$, Clare Gilham ${ }^{4}$, \\ Marta Cecilia Busana ${ }^{4}$, Julian Peto ${ }^{4}$, Isabel dos-Santos-Silva ${ }^{4}$, Hector C Keun ${ }^{1}$ and Olivia Fletcher ${ }^{\star, 2}$ \\ ${ }^{1}$ Faculty of Medicine, Department of Surgery and Cancer, Imperial College, London SW7 2AZ, UK; ${ }^{2}$ Breast Cancer Now Toby \\ Robins Research Centre, The Institute of Cancer Research, 237 Fulham Road, London SW7 3RP, UK; ${ }^{3}$ Department of Life Sciences, \\ Imperial College, London SW7 2AZ, UK and ${ }^{4}$ Department of Non-Communicable Disease Epidemiology, The London School of \\ Hygiene and Tropical Medicine, London WC1E 7HT, UK
}

Background: Endogenous sex hormones are well-established risk factors for breast cancer; the contribution of specific oestrogen metabolites (EMs) and/or ratios of specific EMs is less clear. We have previously identified a CYP3A7* $1 \mathrm{C}$ allele that is associated with lower urinary oestrone $\left(E_{1}\right)$ levels in premenopausal women. The purpose of this analysis was to determine whether this allele was associated with specific pathway EMs.

Methods: We measured successfully $12 \mathrm{EMs}$ in mid-follicular phase urine samples from 30 CYP3A7* 1 C carriers and 30 non-carriers using HPLC-MS/MS.

Results: In addition to having lower urinary $E_{1}$ levels, CYP3A7*1C carriers had significantly lower levels of four of the 2-hydroxylation pathway EMs that we measured (2-hydroxyestrone, $P=1.1 \times 10^{-12}$; 2-hydroxyestradiol, $P=2.7 \times 10^{-7}$; 2-methoxyestrone, $P=1.9 \times 10^{-12}$; and 2-methoxyestradiol, $\left.P=0.0009\right)$. By contrast, $16 \alpha$-hydroxylation pathway EMs were slightly higher in carriers and significantly so for 17 -epiestriol $(P=0.002)$.

Conclusions: The CYP3A7*1C allele is associated with a lower urinary $E_{1}$ levels, a more pronounced reduction in 2-hydroxylation pathway EMs and a lower ratio of 2-hydroxylation:16 $\alpha$-hydroxylation EMs in premenopausal women. To further characterise the association between parent oestrogens, EMs and subsequent risk of breast cancer, characterisation of additional genetic variants that influence oestrogen metabolism and large prospective studies of a broad spectrum of EMs will be required.

Endogenous sex hormones are well-established risk factors for breast cancer. Pooled analyses of data from prospective studies have estimated that a doubling of circulating estradiol $\left(E_{2}\right)$, free $E_{2}$ or $E_{1}$ is associated with a $20-30 \%$ or $30-50 \%$ increase in breast cancer risk in pre- and postmenopausal women, respectively (Key et al, 2002, 2013). The contribution of specific oestrogen metabolites (EMs) to breast cancer risk is less clear. Briefly, interconversion between the parent oestrogens, $E_{2}$ and $E_{1}$ occurs by reversible oxidation at the $17 \alpha$-position of the steroid ring; conversion of parent oestrogens to EMs is by irreversible hydroxylation at the 2-, 4- or 16-positions
(Figure 1; Badawi et al, 2001; Tsuchiya et al, 2005; Samavat and Kurzer, 2015). A recent review, summarising evidence from four prospective studies of oestrogen metabolism and breast cancer risk concluded that there was consistent evidence that enhanced 2-hydroxylation was associated with a reduction in risk of breast cancer that was independent of the strong positive associations of unconjugated parent oestrogens $\left(\mathrm{E}_{2}\right.$ and $\left.\mathrm{E}_{1}\right)$ with breast cancer risk (Ziegler et al, 2015).

In an analysis of single-nucleotide polymorphisms (SNPs) tagging genes that are involved in oestrogen synthesis and

*Correspondence: Dr ○ Fletcher; E-mail: Olivia.Fletcher@icr.ac.uk 


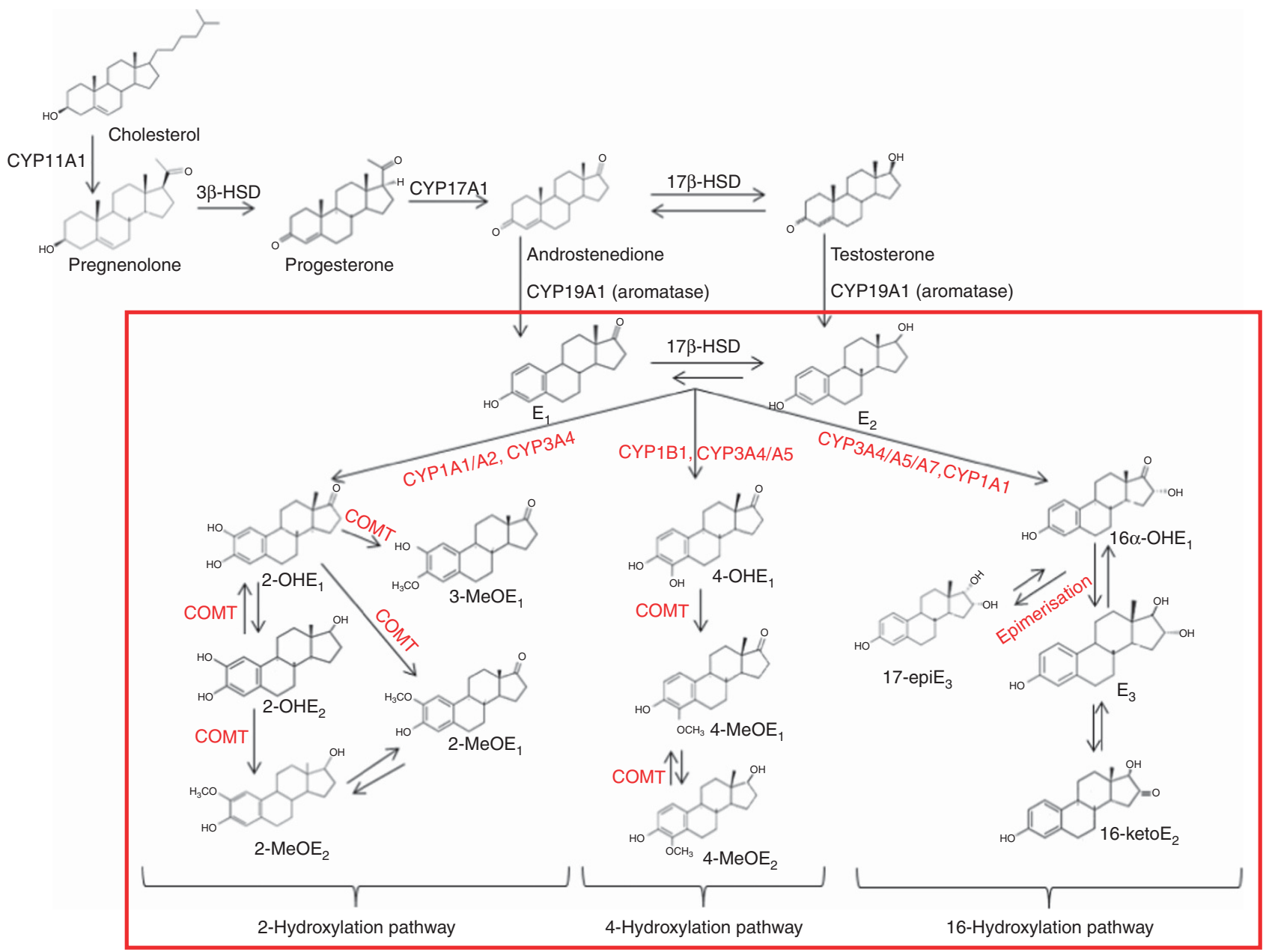

Figure 1. Steroid hormone synthesis and endogenous oestrogen metabolism in humans. The 14 oestrogen metabolites (EMs) formed by hydroxylation of parent oestrogens $\left(E_{1}\right.$ and $\left.E_{2}\right)$, at the 2-, 4- and $16 \alpha$-positions of the carbon ring that were measured are shown within the red box. Enzymes (cytochrome P450 (CYPs) and catechol O-methyltransferase (COMT)) involved in oestrogen metabolism are in red. $E_{1} G$, measured in our previous analysis (Johnson et al, 2012), is an $E_{1}$ conjugate present in urine. The $E_{1}$ measured in this analysis (after hydrolysis of glucuronide and sulphate conjugates in the first step of the LC-MS/MS protocol) is highly correlated with $E_{1} G$ (Spearman's correlation, $\rho=0.70, P<0.0001$ ). Abbreviations: $\mathrm{E}_{1}=$ oestrone; $\mathrm{E}_{2}=$ estradiol; $2-\mathrm{OHE}_{1}=2$-hydroxyestrone; 2-OHE $\mathrm{OH}_{2}=2$-hydroxyestradiol; 2-MeOE $\mathrm{E}_{1}=2$-methoxyestrone; 2- $\mathrm{MeOE}_{2}=2$-methoxyestradiol; 3-MeoE 1 =2-hydroxyestrone-3-methyl ether; 4-OHE $\mathrm{OH}_{1}$ 4-hydroxyestrone; 4-MeOE 1 =4-methoxyestrone; 4- $\mathrm{MeOE}_{2}=4$-methoxyestradiol; $16 \alpha-\mathrm{OHE}_{1}=16 \alpha$-hydroxyestrone; $\mathrm{E}_{3}=$ estriol; $16-\mathrm{Keto}_{2}=16$-ketoestradiol; 17 -epiE $\mathrm{E}_{3}=17$-epiestriol and $17 \beta$-HSD $=17 \beta$-hydroxysteroid.

metabolism, we identified one SNP, rs10273424, which was associated with a $22 \%$ reduction in levels of urinary $\mathrm{E}_{1}$ glucuronide $\left(\mathrm{E}_{1} \mathrm{G}\right)$ in premenopausal women (Johnson et al, 2012). rs10273424 maps to the cytochrome P450 3A (CYP3A) gene cluster at 7q22.1; the CYP3A genes (CYP3A5, CYP3A7 and CYP3A4) encode enzymes that catalyse the oxidative metabolism of a wide range of exogenous and endogenous substrates including parent oestrogens $\left(\mathrm{E}_{1}\right.$ and $\mathrm{E}_{2}$; Figure 1$)$. The metabolic capacity of the CYP3A enzymes differ, depending on the substrate (Williams et al, 2002); with respect to oestrogen metabolism specifically, 2-hydroxylation of $\mathrm{E}_{1}$ to $2-\mathrm{OHE}_{1}$ is catalysed by CYP3A4, 4-hydroxylation to 4$\mathrm{OHE}_{1}$ is catalysed by CYP3A4 and CYP3A5 and $16 \alpha$-hydroxylation to $16 \alpha-\mathrm{OHE}_{1}$ is catalysed by CYP3A4, CYP3A5 and CYP3A7 (Figure 1; Badawi et al, 2001; Lee et al, 2003; Tsuchiya et al, 2005). Fine-mapping of the $7 q 22.1$ association signal for urinary $E_{1} G$ levels implicated the $C Y P 3 A 7^{\star} 1 C$ allele as the causal allele (Johnson et al, 2016). This allele, which comprises seven highly correlated single base changes mapping to the CYP $3 A 7$ promoter, results in expression of the fetal CYP $3 A 7$ gene in adult carriers of the CYP $3 A 7^{\star} 1 C$ allele (Gonzalez, 1988; Kuehl et al, 2001; Burk et al, 2002).
The purpose of this current analysis was to determine whether, in addition to the association between $C Y P 3 A 7^{\star} 1 C$ carrier status and lower urinary $\mathrm{E}_{1} \mathrm{G}$ levels, the $C Y P 3 A 7^{\star} 1 C$ allele was associated with a reduction in levels of specific pathway EMs.

\section{MATERIALS AND METHODS}

Study population. The study population from which the women we included in this analysis were drawn has been described previously (Johnson et al, 2012). Briefly, they comprised 729 premenopausal women who were first-degree relatives and friends of breast cancer cases participating in the British Breast Cancer study (Johnson et al, 2005) or participants in the intervention arm of a trial of annual mammographic screening in young women conducted in Britain (Mammography Oestrogens and Growth Factors Study; Walker et al, 2009). To be eligible, women had to be having regular menstrual cycles, not using hormone replacement therapy or oral contraceptives and not to have been diagnosed with breast cancer at recruitment to the study. All women were of 
self-reported White British ancestry. To be included in the original analysis and this subsequent analysis, women had to have provided serial urine samples (six follicular phase and one luteal phase), at pre-specified days of their menstrual cycle for measurement of creatinine adjusted urinary $\mathrm{E}_{1} \mathrm{G}$ using an in-house enzyme-linked immunosorbent assay (Johnson et al, 2012). To maximise the statistical efficiency of this analysis of the $C Y P 3 A 7^{\star} 1 C$ allele, which has a minor allele frequency (MAF) of just $4 \%$ in Northern European populations (Johnson et al, 2016), we selected 60 women on the basis of genotype; a random sample of $30 C Y P 3 A 7^{\star} 1 C$ carriers and $30 C Y P 3 A 7^{\star} 1 C$ non-carriers. We further selected the two periovulatory samples (samples three and four of the six sequential follicular phase samples) on the basis that oestrogen levels would be at their peak in these samples and this would maximise any differences in levels between $C Y P 3 A 7^{\star} 1 C$ carriers and non-carriers. To minimise random variation, we used the average of these two sequential samples as our outcome variable.

Ethics. The study was conducted in accordance with the tenets of the Declaration of Helsinki and all participants provided written informed consent.

Genotyping. Genotyping of the tag SNP rs45467892, which is perfectly correlated with the $C Y P 3 A 7^{\star} 1 C$ allele, has been described previously (Johnson et al, 2016). Briefly, genotyping was by Taqman (Life Technologies, Paisley, UK). The call rate was $96.9 \%$ and concordance between duplicate samples was $100 \%$.

HPLC-MS/MS analysis. LC-MS/MS analysis was carried out for 14 EMs using the method of (Xu et al, 2005, 2007). We were unable to measure one of the 15 EMs measured by (Xu et al, 2005, 2007) (16-Epiestriol), as there was no commercially available standard for this EM.

Briefly, two aliquots of frozen urine per woman were sent to the Mass Spectroscopy Facility for Quantitative Analysis, Faculty of Natural Science, Imperial College, London, for analysis. Hydrolysis of glucuronide and sulphate-conjugated EMs to form free EMs was carried out by mixing $500 \mu \mathrm{l}$ of freshly thawed urine with $20 \mu \mathrm{l}$ of internal standards (comprising $2 \mathrm{ng}$ of each of five deuteriumlabelled oestrogen metabolites (d-EMs); $17 \beta$-estradiol-d4, estriol$\mathrm{d} 3$, 2-hydroxy-17 $\beta$-estradiol-d5, 2-methoxy-17bestradiol-d5 and 16-epiestriol-d3; Qmx Laboratories Ltd, Dunmow, UK) and $500 \mu \mathrm{l}$ of freshly prepared enzymatic hydrolysis buffer $(100 \mu \mathrm{l}$ of $\beta$-glucuronidase from Helix pomatia (Type H-2; Sigma-Aldrich, St Louis, MO, USA) in $10 \mathrm{ml} 0.15 \mathrm{~m}$ sodium acetate buffer, $\mathrm{pH} 4.6$ containing $2 \mathrm{mg}$ of ascorbic acid). Samples were incubated at $37^{\circ} \mathrm{C}$ overnight before extraction with dichloromethane and dansyl chloride dervitazation. The final derivatised samples $(200 \mu \mathrm{l})$ were transferred to HPLC vials. Urine samples were randomly allocated to one of six analytical batches. Each batch contained 1 matrix blank, 1 matrix blank spiked with internal standards, 8-point calibration standards, 3 quality control (QC) samples and 20 urine samples. QC samples were prepared using charcoal stripped human urine (Golden West Biological Inc., Temecula, CA, USA) with no detectable levels of oestrogen metabolites, spiked with all 14 EMs at a concentration of $2 \mathrm{ng} \mathrm{ml}^{-1}$.

Samples $(10 \mu \mathrm{l})$ were then analysed by HPLC-electrospray ionisation/MS-MS using an Agilent 1100 HPLC coupled to an SCIEX QTRAP 6500 mass spectrometer (AB Sciex LLC, Framingham, MA, USA) running in multiple reaction monitoring (MRM) mode. Chromatographic separation was carried out on a Phenomenex Synergi Hydro-RP $4 \mu \mathrm{m} \times 150 \mathrm{~mm} \times 2.0 \mathrm{~mm}$ column, at $40{ }^{\circ} \mathrm{C}$. The solvent gradient used was $35 \% \mathrm{~A}\left(99.8 \% \mathrm{H}_{2} \mathrm{O}\right.$ : $0.2 \% \mathrm{CHOOH})$ to $85 \% \mathrm{~B}(99.8 \% \mathrm{MeOH}: 0.2 \% \mathrm{CHOOH})$ over $60 \mathrm{~min}$. Solvent B was held at $85 \%$ for $4 \mathrm{~min}$, then the solvent returned to $35 \% \mathrm{~A}$ for $10 \mathrm{~min}$ equilibration before the next injection. The solvent flow rate was $250 \mu \mathrm{lmin}^{-1}$. The ESI source (type: Ion Drive Turbo V) parameters were set to the following:
TEM $500{ }^{\circ} \mathrm{C}$, Curtain Gas 45 psi, GS1 50 psi, GS2 60 psi and MS parameters were CAD gas Medium, DP 80, EP 10, CE 45 and CXP 5. A scheduled detection method was used and the MRM detection window was $120 \mathrm{~s}$ with a target scan time of $1 \mathrm{~s}$. Transitions and retention times are listed in Supplementary Table 1.

Analyst 1.6.2 software (AB Sciex LLC) was used for quantification of the EMs. Peak quantifications were carried out using d-EM internal standards and constructing matrix matched (charcoal stripped human urine) eight-point calibration curves for each of the six analytical batches. The calibration curves were evaluated by plotting the peak area ratios of dansyl-EM/d-dansyl-EM against concentration ( $\mathrm{ng} \mathrm{ml}^{-1}$ ) of EMs in the standard and using linear regression with $1 / X$ weighting to fit the data. Using this linear function, the amounts of EMs in the urine sample were interpolated.

The intra- and inter-batch coefficients of variation (CVs), evaluated from three QC samples per analytical batch, in six independent consecutive batches $(N=18$ QC samples) ranged from $6 \%$ to $10 \%$ (intra-batch CV) and $6 \%$ to $14 \%$ (inter-batch CV; Supplementary Table 2). The two highest inter-batch CVs were for 4-methoxyestrone (14\%) and 4-methoxyestradiol (13\%), the two oestrogen metabolites that had the lowest concentrations and which were subsequently excluded from the analysis. The LLOQ was estimated as $80 \mathrm{pg} \mathrm{ml}^{-1}$, where the intra- and inter-batch precision of all the EMs were consistently $<10 \%$ and the intra- and inter batch accuracies were between 97 and 105\%. The LOD for the entire assay (all $14 \mathrm{EMs}$ ) was estimated to be $8 \mathrm{pg} \mathrm{ml}^{-1}$.

Statistical analysis. EMs were converted from $\mathrm{ng} \mathrm{ml}^{-1}$ of urine to $\mathrm{pg} \mathrm{mg}^{-1}$ creatinine using the molecular weight of the unconjugated form of each of the EMs and the amount of creatinine (measured in $\mathrm{mg} \mathrm{ml}^{-1}$ ) for each of the samples. This allowed us to create pathway variables as described by Faupel-Badger et al (2010). Where both of the two samples per woman were measured successfully, we used the mean of the two measurements; where one of two measurements from a woman was missing, we used the one available measurement; where both measurements were missing, we excluded the woman from the analysis of this EM. For the majority of EMs, there were no missing values. For four EMs (2-hydroxyestrone (2-OHE1), 2-methoxyestradiol $\left(2-\mathrm{MeOE}_{2}\right), 2$-hydroxyestrone-3-methyl ether $\left(3-\mathrm{MeOE}_{1}\right)$ and 16 -ketoestradiol $\left.\left(16-\mathrm{ketoE}_{2}\right)\right)$, there were $<10 \%$ missing values (Supplementary Table 3). For two EMs (4-methoxyestrone $\left(4-\mathrm{MeOE}_{1}\right)$ and 4-methoxyestradiol $\left.\left(4-\mathrm{MeOE}_{2}\right)\right)$, levels were undetectable in the majority of samples $(92(76.7 \%)$ and 107 $(89.2 \%)$ for $4-\mathrm{MeOE}_{1}$ and $4-\mathrm{MeOE}_{2}$, respectively). These two EMs were excluded from further analysis. For the 12 EMs that we were able to measure, we estimated the within-woman variation based on the two sequential samples per woman; intra-class correlation coefficients for individual EMs and grouped EMs are shown in Supplementary Table 4.

For individual and pathway EMs, we calculated geometric means and 95\% confidence intervals (CIs) on the natural logarithm scale and exponentiated the values back to the original scale. Linear regression models of the $\log _{\mathrm{e}}$-transformed EMs were used to estimate per cent differences between $C Y P 3 A 7^{\star} 1 C$ carriers and non-carriers for individual and pathway EMs. We carried out unadjusted analyses and analyses that were adjusted for measurement batch (1-6), body mass index (BMI; quartiles), age at first full-term pregnancy (quartiles) and parity $(0,1-2,>2)$. Adjustment for these covariates did not alter effect sizes substantially and, therefore, unadjusted results are presented. We used $t$-tests of the linear regression coefficient to estimate $P$-values. We applied a Bonferroni correction to establish a statistical significance level of $P<0.003$, based on our measuring of 14 individual EMs and 5 grouped EMs. Statistical analyses were carried out using 
R (version 3.2.3; http://cran.r-project.org). All reported $P$-values are two-sided.

\section{RESULTS}

Characteristics of the 60 women who were included in this analysis are presented in Table 1; there were no differences between $C Y P 3 A 7^{\star} 1 C$ carriers and non-carriers. Levels of EMs in $C Y P 3 A 7^{*} 1 C$ carriers and non-carriers are shown in Figure 2 (full details of individual EMs, grouped EMs and ratios of EMs are in Supplementary Table 3). The predominant oestrogen/EMs were estriol $\left(\mathrm{E}_{3}\right), \mathrm{E}_{1}$ and 2-hydroxyestrone (2-OHE $\left.\mathrm{H}_{1}\right)$ with geometric mean concentrations in non-carriers of 63.6, 28.6 and $21.8 \mathrm{pmol} \mathrm{mg}^{-1}$ creatinine, respectively. The least abundant EMs were the methylated 2-catechol EMs, 2-methoxyestradiol $\left(2-\mathrm{MeOE}_{2}\right)$ and 2 -Hydroxyestrone-3-methyl ether $\left(3-\mathrm{MeOE}_{1}\right)$ and

Table 1. Characteristics of the 30 CYP $3 A 7 * 1 C$ carriers and 30 CYP3A7*1C non-carriers included in this analysis

\begin{tabular}{|l|c|c|c|}
\hline & $\begin{array}{c}\text { CYP3A7*1C } \\
\text { non-carriers }\end{array}$ & $\begin{array}{c}\text { CYP3A7*1C } \\
\text { carriers }\end{array}$ & P-value \\
\hline Age at urine collection & $44.1(16-53)$ & $45.5(27-50)$ & 0.38 \\
\hline BMI at urine collection & $24.0(19.2-39.9)$ & $25.5(18.3-39.0)$ & 0.64 \\
\hline Parity & $10(33.3)$ & $6(20.0)$ & \\
Nulliparous & $17(56.7)$ & $15(50.0)$ & \\
1-2 Children & $3(10.0)$ & $9(30.0)$ & 0.13 \\
>2 Children & $26.3(20-31)$ & $27.2(17-32)$ & 0.39 \\
$\begin{array}{l}\text { Age at first full-term } \\
\text { pregnancy }\end{array}$ & & & \\
\hline A & & & \\
\hline
\end{tabular}

Abbreviation: $\mathrm{BMI}=$ body mass index .

an parous women. For quantitative traits (age at urine collection, BMI at urine collection and age at first full-term pregnancy), means and ranges are presented. For parity, the number and percentage of women in each category is shown. For quantitative traits, $P$-values were from $t$-tests; for parity, the $P$-value was from a Fisher's exact test.
17-Epiestriol (17-epiE 3 ) with geometric mean concentrations in non-carriers of $0.67,0.74$ and $0.31 \mathrm{pmol} \mathrm{mg}^{-1}$ creatinine, respectively. Levels of the methylated 4-catechol EMs, 4-methoxyestrone $\left(4-\mathrm{MeOE}_{1}\right)$ and 4-methoxyestradiol $\left(4-\mathrm{MeOE}_{2}\right)$ were below the limits of detection in $92(76.7 \%)$ and 107 (89.2\%) of the 120 samples that we assayed.

Comparing $C Y P 3 A 7^{\star} 1 C$ carriers with non-carriers, levels of the parent oestrogen $\mathrm{E}_{1}$ were $45.3 \%$ lower in $C Y P 3 A 7^{\star} 1 C$ carriers $\left(P=0.0005\right.$, Table 2). For the two catechol EMs $\left(2-\mathrm{OHE}_{1}\right.$ and $\left.2-\mathrm{OHE}_{2}\right)$ and the methylated two catechol EMs $\left(2-\mathrm{MeOE}_{1}\right.$ and $\left.2-\mathrm{MeOE}_{2}\right)$, the reduction in urinary levels was more extreme; compared with non-carriers, levels in $C Y P 3 A 7^{\star} 1 C$ carriers were $-78.3 \%\left(P=1.1 \times 10^{-12}\right),-67.9 \%\left(P=2.7 \times 10^{-7}\right),-81.2 \%$ $\left(P=1.9 \times 10^{-12}\right)$ and $-62.8 \%(P=0.0009)$ for $2-\mathrm{OHE}_{1}, 2-\mathrm{OHE}_{2}$, $2-\mathrm{MeOE}_{1}$ and $2-\mathrm{MeOE}_{2}$, respectively (Table 2). By contrast, levels of the 16-pathway EMs were slightly higher in $C Y P 3 A 7^{\star} 1 C$ carriers, that is, $+25.5 \%(P=0.11),+91.6 \%(P=0.007)$ and $+160.1 \%(P=0.002)$ higher for $E_{3}, 16 \alpha$-hydroxyestrone $(16 \alpha$ $\mathrm{OHE}_{1}$ ) and 17-epiE 3 , respectively (Table 2). Adjusting for measurement batch, BMI, age at first full-term pregnancy and parity did not alter these results substantially (Supplementary Table 5).

EMs from the three different oestrogen metabolism pathways (2-hydroxylation, 4-hydroxylation and 16 $\alpha$-hydroxylation) have been associated with different oestrogenic and genotoxic properties (Faupel-Badger et al, 2010; Ziegler et al, 2015) with a high 2-hydroxylation:16 $\alpha$-hydroxylation pathway ratio, generally being considered to be associated with a reduction in breast cancer risk. Comparing $C Y P 3 A 7^{\star} 1 C$ carriers with non-carriers, the $2-\mathrm{OHE}_{1}: 16 \alpha-\mathrm{OHE}_{1}$ ratio in carriers $(0.39,95 \%$ CI: $0.26-0.57)$ was significantly lower than the ratio in non-carriers $(3.86,95 \% \mathrm{CI}$ : 2.53-5.89; $P=1.0 \times 10^{-11}$; Supplementary Table 3). Similarly, combining all 2-hydroxylation pathway and $16 \alpha$-hydroxylation pathway metabolites, the ratio in $C Y P 3 A 7^{\star} 1 C$ carriers $(0.10,95 \%$ CI: $0.07-0.13)$ was much lower than the ratio in non-carriers $(0.51$, 95\% CI: 0.38-0.67; P $=1.7 \times 10^{-9}$; Supplementary Table 3).

\section{DISCUSSION}

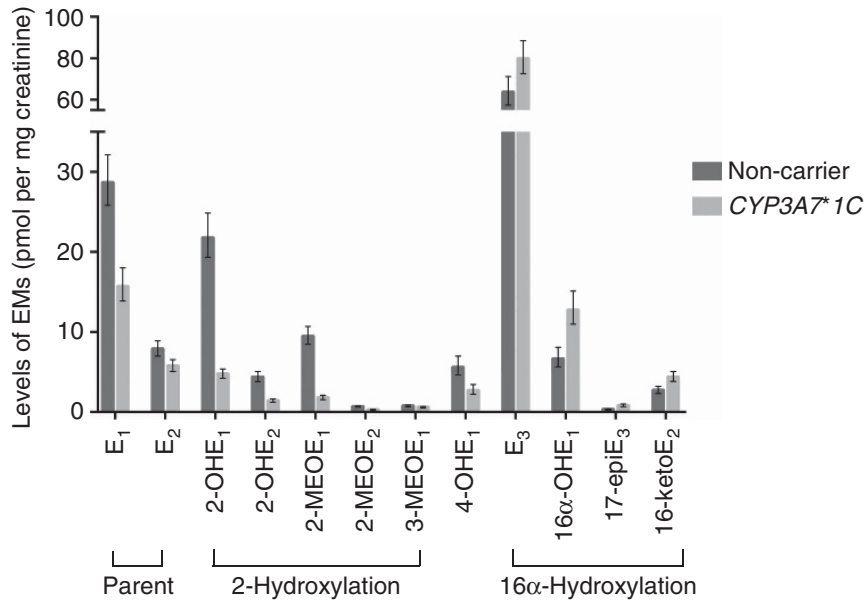

Figure 2. Geometric mean levels (pmol mg ${ }^{-1}$ creatinine) of $12 \mathrm{EMs}$ that we measured in urine samples from 60 premenopausal women; 30 carriers of the CYP $3 A 7^{\star} 1 C$ allele (light grey) and 30 non-carriers (dark grey). Estimates are the average of two samples per woman, taken on sequential days, calculated to be at or around ovulation based on the woman's usual menstrual cycle length. Error bars represent s.e. Levels of two of the 4-hydroxylation pathway EMs (4-MeOE ${ }_{1}$ and 4- $\left.\mathrm{MeOE}_{2}\right)$ were below detection in $92\left(4-\mathrm{MeOE}_{1}\right)$ and $107\left(4-\mathrm{MeOE}_{2}\right)$ of the samples analysed. These two EMs were, therefore, excluded.
To our knowledge, comprehensive data on urinary EMs in premenopausal women, measured using LC-MS, have been previously reported in three studies (Eliassen et al, 2009, 2012; Faupel-Badger et al, 2010; Maskarinec et al, 2012). The first of these was the Nurses' Health Study II, a prospective study of North American registered nurses aged 25-42 years at recruitment (Eliassen et al, 2009, 2012). The second was a population-based study of incident breast cancer among women of Asian ancestry living in California and Hawaii (Faupel-Badger et al, 2010) and the third was a randomised trial of the effect of consuming soy foods on hormonal outcomes, conducted in women of Caucasian, Native Hawaiian and Asian ancestry, and living in Hawaii (Maskarinec et al, 2012).

Comparing absolute levels of EMs in our study with those reported by these other studies is not straightforward. Levels of individual EMs and all EMs combined may differ between ethnicities (Maskarinec et $a l, 2012$ ) and women from several different ethnicities have been included in the reports to date (Asian, Faupel-Badger et al (2010); African-American, Asian, Hispanic and Caucasian, Eliassen et al (2012); Caucasian, Native Hawaiian and Asian, Maskarinec et al (2012)). In addition, the 30 non-carriers that we analysed may not be representative of the general British population, as they were selected on genotype (with a MAF of $4 \%$, we would expect $2.2 C Y P 3 A 7^{\star} 1 C$ carriers in a population-based sample of 30 women) and $6(20 \%)$ were firstdegree relatives of breast cancer cases, suggesting that they may be 
Table 2. Percentage difference $(95 \% \mathrm{CI})$ in urinary EM levels comparing CYP3A7*1C carriers with non-carriers

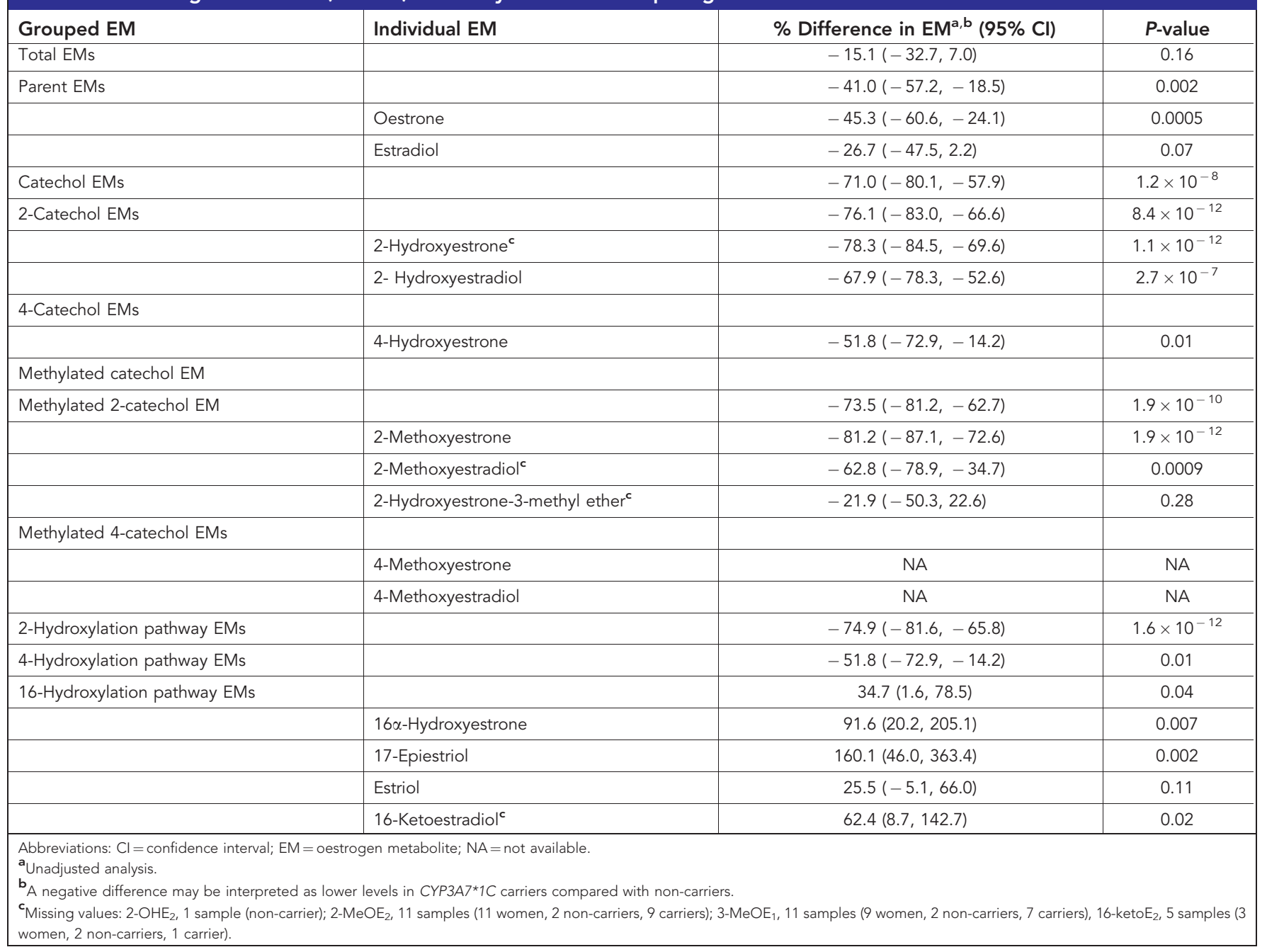

at higher risk than the general population. Our analysis is based on the average of two periovulatory samples, Faupel-Badger et al (2010) analysed both non-luteal phase and luteal phase samples, whereas the studies reported by Eliassen et al $(2009,2012)$ and Maskarinec et al (2012) focussed on luteal phase samples. There is, however, no evidence that the $2-\mathrm{OHE}_{1}: 16 \alpha-\mathrm{OHE}_{1}$ ratio differs according to the phase of the menstrual cycle (Faupel-Badger et al, 2010). Comparing this ratio across studies, the $2-\mathrm{OHE}_{1}: 16 \alpha-\mathrm{OHE}_{1}$ ratio in our non-carriers (3.9) was similar to the $2-\mathrm{OHE}_{1}: 16 \alpha$ $\mathrm{OHE}_{1}$ ratios reported by Faupel-Badger et al (2010) (2.2 and 2.1 in luteal phase and non-luteal phase samples, respectively) and by Eliassen et al (2012) (4.35) but somewhat lower than the ratios reported by Maskarinec et al (2012) (8.4 and 13.0 in Asian and non-Asians, respectively).

We have previously demonstrated that the $C Y P 3 A 7^{\star} 1 C$ allele is associated with lower levels of urinary $\mathrm{E}_{1} \mathrm{G}$ (Johnson et al, 2016). Here we have demonstrated that $C Y P 3 A 7^{*} 1 C$ carriers have a more pronounced reduction in 2-hydroxylation pathway EMs, increased $16 \alpha$-hydroxylation pathway EMs and markedly reduced two-hydroxylation pathway:16 $\alpha$-hydroxylation pathway ratios as measured by the $2-\mathrm{OHE}_{1}: 16 \alpha-\mathrm{OHE}_{1}$ ratio $\left(0.39\right.$ in $C Y P 3 A 7^{\star} 1 C$ carriers compared with population estimates of 2.1-13.0) or all 2- and 16 $\alpha$-pathway metabolites combined ( 0.10 in $C Y P 3 A 7^{\star} 1 C$ carriers compared with population estimates of 0.90 or 0.96 (Eliassen et al, 2009, 2012)). Our data are consistent with expression of the foetal CYP3A7 gene in adult carriers of the $C Y P 3 A 7^{\star} 1 C$ allele resulting in (i) a modest reduction in levels of the parent oestrogen $\mathrm{E}_{1}$ and (ii) a specific bias towards $16 \alpha$-hydroxylation (which can be catalysed by CYP3A7) over 2- or 4- hydroxylation (which are not catalysed by CYP3A7 (Lee et al, 2003)).

In their recent review of oestrogen metabolism and breast cancer, Ziegler et al (2015) concluded that the combined evidence from prospective studies using LC-MS to measure EMs in prediagnostic serum, plasma and urine was consistent with the hypothesis that enhanced 2-hydroxylation is associated with reduced risk of breast cancer. They further concluded that the inverse association with enhanced 2-hydroxylation (specifically 2hydroxylation: $16 \alpha$-hydroxylation and 2 -hydroxylation:parent oestrogens ratios) was independent of the strong positive associations between unconjugated $E_{2}$ and $E_{1}$ with postmenopausal breast cancer risk (Ziegler et al, 2015). Our analysis supports these conclusions if we assume that breast cancer risk in carriers of the $C Y P 3 A 7^{\star} 1 C$ allele is influenced by two components with opposite effects. Based on the combined evidence of prospective studies of premenopausal hormone levels and breast cancer risk, lifetime lower levels of $\mathrm{E}_{1}$ and $\mathrm{E}_{2}$ of $\sim 45 \%$ and $27 \%$ in carriers of the $C Y P 3 A 7^{\star} 1 C$ allele would be predicted to result in a substantial reduction in risk for these individuals. By contrast, an unfavourable (reduced) 2-hydroxylation:16 $\alpha$-hydroxylation ratio would be expected to increase risk. Our previous analyses demonstrate that the reduction in breast cancer risk for carriers of the rare allele of rs10235235 (which is correlated with the $C Y P 3 A 7^{\star} 1 C$ allele $r^{2}=0.25, D^{\prime}=1.0$ ) is very modest (heterozygote $\mathrm{OR}=0.98$, $P=0.2$; homozygote $\mathrm{OR}=0.80, P=0.004$; Johnson et al, 2014) 
consistent with an unfavourable (reduced) 2-hydroxylation:16 $\alpha$ hydroxylation counteracting a potentially more substantial beneficial effect of lower levels of parent oestrogens.

Strengths of our study include our comprehensive analysis of urinary EMs using HPLC-MS/MS and, as genotypes are effectively randomised at birth (Ebrahim and Davey Smith, 2008), our focus on a genetic variant (the $C Y P 3 A 7^{\star} 1 C$ allele), which minimises the potential for confounding by unmeasured environmental factors. There are several limitations to our study; owing to the frequency of the $C Y P 3 A 7^{\star} 1 C$ allele, the numbers are small and, given our selection procedure, the non-carriers may not be representative of the White British population. Our choice of using two consecutive periovulatory samples makes it difficult to compare EM levels in our study with other published reports, which have mainly analysed a single luteal phase sample (Eliassen et al, 2009, 2012; Faupel-Badger et al, 2010; Maskarinec et al, 2012). In addition, we do not have prospective data on $C Y P 3 A 7^{\star} 1 C$ carrier status, hormone levels and breast cancer risk in large numbers of women, and we cannot compare breast cancer risk in women with low levels of the parent oestrogen $\mathrm{E}_{1}$ according to their $C Y P 3 A 7^{\star} 1 C$ status (and hence 2hydroxylation: $16 \alpha$-hydroxylation ratio) directly.

In conclusion, we have demonstrated that the $C Y P 3 A 7^{\star} 1 C$ allele has a profound effect on levels of the parent oestrogen $E_{1}$ and the ratio of 2-hydroxylation:16 $\alpha$-hydroxylation EMs in premenopausal women. To characterise the association between parent oestrogens, EMs and subsequent risk of breast cancer fully, identification of additional genetic variants that influence parent oestrogens and particular pathway EMs, and further prospective studies that analyse a broad spectrum of EMs will be required.

\section{ACKNOWLEDGEMENTS}

NJ and OF are funded by Breast Cancer Now. The Mammography Oestrogens and Growth factors study was funded by Cancer Research UK grants C405/A2144 and C405/A14565; the latter also provided support for MCB. JP and CG are funded by Cancer Research UK (C1178/A10292). HK, DS and AS are supported by the EC FP7 project HELIX (grant agreement number 603864). PJ is supported by the EC FP7 project EXPOSOMICS (grant agreement number 308610).

\section{CONFLICT OF INTEREST}

The authors declare no conflict of interest.

\section{REFERENCES}

Badawi AF, Cavalieri EL, Rogan EG (2001) Role of human cytochrome P450 $1 \mathrm{~A} 1,1 \mathrm{~A} 2,1 \mathrm{~B} 1$, and $3 \mathrm{~A} 4$ in the 2-, 4-, and 16alpha-hydroxylation of 17beta-estradiol. Metabolism 50(9): 1001-1003.

Burk O, Tegude H, Koch I, Hustert E, Wolbold R, Glaeser H, Klein K, Fromm MF, Nuessler AK, Neuhaus P, Zanger UM, Eichelbaum M, Wojnowski L (2002) Molecular mechanisms of polymorphic CYP3A7 expression in adult human liver and intestine. J Biol Chem 277(27): 24280-24288.

Ebrahim S, Davey Smith G (2008) Mendelian randomization: can genetic epidemiology help redress the failures of observational epidemiology? Hum Genet 123(1): 15-33.

Eliassen AH, Spiegelman D, Xu X, Keefer LK, Veenstra TD, Barbieri RL, Willett WC, Hankinson SE, Ziegler RG (2012) Urinary estrogens and estrogen metabolites and subsequent risk of breast cancer among premenopausal women. Cancer Res 72(3): 696-706.

Eliassen AH, Ziegler RG, Rosner B, Veenstra TD, Roman JM, Xu X, Hankinson SE (2009) Reproducibility of fifteen urinary estrogens and estrogen metabolites over a 2- to 3-year period in premenopausal women. Cancer Epidemiol Biomarkers Prev 18(11): 2860-2868.
Faupel-Badger JM, Fuhrman BJ, Xu X, Falk RT, Keefer LK, Veenstra TD, Hoover RN, Ziegler RG (2010) Comparison of liquid chromatographytandem mass spectrometry, RIA, and ELISA methods for measurement of urinary estrogens. Cancer Epidemiol Biomarkers Prev 19(1): 292-300.

Gonzalez FJ (1988) The molecular biology of cytochrome P450s. Pharmacol Rev 40(4): 243-288.

Johnson N, De Ieso P, Migliorini G, Orr N, Broderick P, Catovsky D, Matakidou A, Eisen T, Goldsmith C, Dudbridge F, Peto J, Dos-SantosSilva I, Ashworth A, Ross G, Houlston RS, Fletcher O (2016) Cytochrome P450 allele CYP3A $7{ }^{\star} 1 \mathrm{C}$ associates with adverse outcomes in chronic lymphocytic leukemia, breast, and lung cancer. Cancer Res 76(6): 1485-1493.

Johnson N, Dudbridge F, Orr N, Gibson L, Jones ME, Schoemaker MJ, Folkerd EJ, Haynes BP, Hopper JL, Southey MC, Dite GS, Apicella C, Schmidt MK, Broeks A, Van't Veer LJ, Atsma F, Muir K, Lophatananon A, Fasching PA, Beckmann MW, Ekici AB, Renner SP, Sawyer E, Tomlinson I, Kerin M, Miller N, Burwinkel B, Marme F, Schneeweiss A, Sohn C, Guenel P, Truong T, Cordina E, Menegaux F, Bojesen SE, Nordestgaard BG, Flyger H, Milne R, Zamora MP, Arias Perez JI, Benitez J, Bernstein L, Anton-Culver H, Ziogas A, Clarke Dur C, Brenner H, Muller H, Arndt V, Dieffenbach AK, Meindl A, Heil J, Bartram CR, Schmutzler RK, Brauch H, Justenhoven C, Ko YD, Network G, Nevanlinna H, Muranen TA, Aittomaki K, Blomqvist C, Matsuo K, Dork T, Bogdanova NV, Antonenkova NN, Lindblom A, Mannermaa A, Kataja V, Kosma VM, Hartikainen JM, Chenevix-Trench G, Beesley J, kConFab I, Australian Ovarian Cancer Study G, Wu AH, Van den Berg D, Tseng CC, Lambrechts D, Smeets D, Neven P, Wildiers H, Chang-Claude J, Rudolph A, Nickels S, Flesch-Janys D, Radice P, Peterlongo P, Bonanni B, Pensotti V, Couch FJ, Olson JE, Wang X, Fredericksen Z, Pankratz VS, Giles GG, Severi G, Baglietto L, Haiman C, Simard J, Goldberg MS, Labreche F, Dumont M, Soucy P, Teo S, Yip CH, Phuah SY, Cornes BK, Kristensen VN, Grenaker Alnaes G, Borresen-Dale AL, Zheng W, Winqvist R, Pylkas K, Jukkola-Vuorinen A, Grip M, Andrulis IL, Knight JA, Glendon G, Mulligan AM, Devillee P, Figueroa J, Chanock SJ, Lissowska J, Sherman ME, Hall P, Schoof N, Hooning M, Hollestelle A, Oldenburg RA, Tilanus-Linthorst M, Liu J, Cox A, Brock IW, Reed MW, Cross SS, Blot W, Signorello LB, Pharoah PD, Dunning AM, Shah M, Kang D, Noh DY, Park SK, Choi JY, Hartman M, Miao H, Lim WY, Tang A, Hamann U, Forsti A, Rudiger T, Ulmer HU, Jakubowska A, Lubinski J, Jaworska-Bieniek K, Durda K, Sangrajrang S, Gaborieau V, Brennan P, McKay J, Slager S, Toland AE, Vachon C, Yannoukakos D, Shen CY, Yu JC, Huang CS, Hou MF, Gonzalez-Neira A, Tessier DC, Vincent D, Bacot F, Luccarini C, Dennis J, Michailidou K, Bolla MK, Wang J, Easton DF, Garcia-Closas M, Dowsett M, Ashworth A, Swerdlow AJ, Peto J, dos Santos Silva I, Fletcher O (2014) Genetic variation at CYP3A is associated with age at menarche and breast cancer risk: a case-control study. Breast Cancer Res 16(3): R51.

Johnson N, Fletcher O, Naceur-Lombardelli C, dos Santos Silva I, Ashworth A, Peto J (2005) Interaction between CHEK2*1100delC and other low-penetrance breast-cancer susceptibility genes: a familial study. Lancet 366(9496): 1554-1557.

Johnson N, Walker K, Gibson LJ, Orr N, Folkerd E, Haynes B, Palles C, Coupland B, Schoemaker M, Jones M, Broderick P, Sawyer E, Kerin M, Tomlinson IP, Zvelebil M, Chilcott-Burns S, Tomczyk K, Simpson G, Williamson J, Hillier SG, Ross G, Houlston RS, Swerdlow A, Ashworth A, Dowsett M, Peto J, Dos Santos Silva I, Fletcher O (2012) CYP3A variation, premenopausal estrone levels, and breast cancer risk. J Natl Cancer Inst 104(9): 657-669.

Key T, Appleby P, Barnes I, Reeves G, Endogenous H, Breast Cancer Collaborative Group (2002) Endogenous sex hormones and breast cancer in postmenopausal women: reanalysis of nine prospective studies. $J$ Natl Cancer Inst 94(8): 606-616.

Key TJ, Appleby PN, Reeves GK, Travis RC, Alberg AJ, Barricarte A, Berrino F, Krogh V, Sieri S, Brinton LA, Dorgan JF, Dossus L, Dowsett M, Eliassen AH, Fortner RT, Hankinson SE, Helzlsouer KJ, Hoff man-Bolton J, Comstock GW, Kaaks R, Kahle LL, Muti P, Overvad K, Peeters PH, Riboli E, Rinaldi S, Rollison DE, Stanczyk FZ, Trichopoulos D, Tworoger SS, Vineis P (2013) Sex hormones and risk of breast cancer in premenopausal women: a collaborative reanalysis of individual participant data from seven prospective studies. Lancet Oncol 14(10): 1009-1019.

Kuehl P, Zhang J, Lin Y, Lamba J, Assem M, Schuetz J, Watkins PB, Daly A, Wrighton SA, Hall SD, Maurel P, Relling M, Brimer C, Yasuda K, 
Venkataramanan R, Strom S, Thummel K, Boguski MS, Schuetz E (2001) Sequence diversity in CYP3A promoters and characterization of the genetic basis of polymorphic CYP3A5 expression. Nat Genet 27(4): 383-391.

Lee AJ, Conney AH, Zhu BT (2003) Human cytochrome P450 3A7 has a distinct high catalytic activity for the 16alpha-hydroxylation of estrone but not 17beta-estradiol. Cancer Res 63(19): 6532-6536.

Maskarinec G, Heak S, Morimoto Y, Custer L, Franke AA (2012) The relation of urinary estrogen metabolites with mammographic densities in premenopausal women. Cancer Epidemiol 36(5): e310-e316.

Samavat H, Kurzer MS (2015) Estrogen metabolism and breast cancer. Cancer Lett 356(2 Pt A): 231-243.

Tsuchiya Y, Nakajima M, Yokoi T (2005) Cytochrome P450-mediated metabolism of estrogens and its regulation in human. Cancer Lett 227(2): $115-124$.

Walker K, Fletcher O, Johnson N, Coupland B, McCormack VA, Folkerd E, Gibson L, Hillier SG, Holly JM, Moss S, Dowsett M, Peto J, dos Santos Silva I (2009) Premenopausal mammographic density in relation to cyclic variations in endogenous sex hormone levels, prolactin, and insulin-like growth factors. Cancer Res 69(16): 6490-6499.
Williams JA, Ring BJ, Cantrell VE, Jones DR, Eckstein J, Ruterbories K, Hamman MA, Hall SD, Wrighton SA (2002) Comparative metabolic capabilities of CYP3A4, CYP3A5, and CYP3A7. Drug Metab Dispos 30(8): 883-891.

Xu X, Keefer LK, Ziegler RG, Veenstra TD (2007) A liquid chromatographymass spectrometry method for the quantitative analysis of urinary endogenous estrogen metabolites. Nat Protoc 2(6): 1350-1355.

Xu X, Veenstra TD, Fox SD, Roman JM, Issaq HJ, Falk R, Saavedra JE, Keefer LK, Ziegler RG (2005) Measuring fifteen endogenous estrogens simultaneously in human urine by high-performance liquid chromatography-mass spectrometry. Anal Chem 77(20): 6646-6654.

Ziegler RG, Fuhrman BJ, Moore SC, Matthews CE (2015) Epidemiologic studies of estrogen metabolism and breast cancer. Steroids 99(Pt A): $67-75$.

(c) (i) This work is licensed under the Creative Commons Attribution 4.0 International License. To view a copy of this license, visit http://creativecommons.org/licenses/by/4.0/

(C) The Author(s) named above 2017

Supplementary Information accompanies this paper on British Journal of Cancer website (http://www.nature.com/bjc) 